\title{
THE USE OF FAKE DOCUMENTS AND THE RESULTS OF THIS STATUS
}

\author{
DOI: 10.17261/Pressacademia.2019.1083 \\ PAP- V.9-2019(30)-p.150-154
}

Oguz Yurt ${ }^{1}$, Suat Teker ${ }^{2}$

${ }^{1}$ Işık University, Institue of Social Sciences, Maslak, İstanbul. Turkey. yurt.oguz@gmail.com, ORCID: 0000-0003-0377-1065

${ }^{1}$ Işık University, Maslak Campus, ìstanbul. Turkey.

suat.teker@isikun.edu.tr, ORCID: 0000-0002-7981-3121

\section{To cite this document}

Yurt, O., Teker, S. (2019). The use of fake documents and the results of this status. PressAcademia Procedia (PAP), V.9, p.150-154

Permemant link to this document: http://doi.org/10.17261/Pressacademia.2019.1083

Copyright: Published by PressAcademia and limited licenced re-use rights only.

\section{ABSTRACT}

Purpose- The purpose of this research is to investigate the fake documents used by businesses and their impact on businesses.

Methodology- Necessary legal information and recommendations were mentioned in the study and the effects of the use of counterfeit documents were tried to be explained. Company information is kept confidential in case study due to company privacy.

Findings- Taxes and penalties to be levied are stated in accordance with the tax legislation.

Conclusion- It was concluded that enterprises using false documents faced serious material and moral sanctions in the continuation of this determination.

Keywords: False document, misleading document by contents, tax loss.

JEL Codes: M40, M42.

\section{IŞLETMELERDE SAHTE BELGE KULLANMA DURUMU VE BU DURUMUN SONUÇLARI}

\section{ÖZET}

Amaç- Bu araştırmanın amacı, işletmeler tarafından kullanılan sahte belgeler ve bunların işletmelere olan etkisi konusu incelenmektedir. Yöntem- Araştırmada gerekli yasal bilgiler ve öneriler belirtilmiş olup örnek sahte belge kullanma durumu üzerinden etkileri anlatılmaya çalışılmıştır. Şirket mahremiyeti gereği örnek olay incelemesinde firma bilgileri gizli tutulmuştur.

Bulgular- Vergi mevzuatı gereğince tarh edilmesi gerek vergiler ve kesilmesi gereken cezalar belirtilmiştir.

Sonuç- Sahte belge kullanan işletmeler bu durumun tespit edilmesinin devamında çok ciddi maddi ve manevi yaptırımlarla karşı karşıya kaldığı sonucuna ulaşılmıştır.

Anahtar Kelimeler: Sahte belge, muhteviyatı itibariyle yanıltıcı belge, vergi ziyaı.

JEL Kodları: M40, M42

\section{GiRiş}

Kamu hizmetlerinin temel finansman kaynağı olan vergiler, devlet için hayati öneme sahiptir. Ancak aynı zamanda vergiler, hem maddi açıdan hem de yerine getirilmesi ödevler bakımından mükelleflerin üzerinde ciddi bir yük oluşturmaktadır. Mükellefler, bu yükten kurtulmak için çeşitli hile ve yöntemlere başvurmaktadırlar (Akdeniz 2018:90).

Vergi kanunlarımızda sahte belge olarak tanımlanan, ticari hayatta ise naylon fatura olarak bilinen belgeler ve bunların kullanılması (yasal defterler kayıt edilmesi) halinde işletmelerin karşılaşacakları durumlar ile sahte belgenin ne olduğu, işletmeler tarafından neden kullanıldığı, bunların nasıl anlaşılabileceği ve sahte belge kullanmanın yasal yaptırımları, örnek bir olay incelemesiyle anlatılmıştır. 


\section{LITERATÜR INCELEMESI}

\subsection{Sahte Belge}

Sahte Belgenin tanımı ilk olarak 28 Seri No.lu KDV Genel Tebliğinde belirtilmiştir. Buna göre, hukuki geçerliliği sağlayan zorunlu ve yeterli unsurlara sahip olmayan belgeler sahte belgedir. Bu çerçevede;

-Mal hareketi veya hizmet söz konusu olmadan düzenlenen belgeler,

-Belge düzenleme yetkisi bulunmayanlar tarafından düzenlenen belgeler,

-Başkaları adına bastırılıp kullanılan belgeler sahte belge olarak kabul edilir.

213 Sayılı Vergi Usul Kanununun 359. maddesinde ise; Gerçek bir muamele veya durum olmadığı halde bunlar varmış gibi düzenlenen belge, sahte belgedir şeklinde tanımlama yapılmıştır.

\subsection{Muhteviyatı İtibariyle Yanıltıcı Belge}

213 Sayılı Vergi Usul Kanununun 359. maddesinde; Gerçek bir muamele veya duruma dayanmakla birlikte bu muamele veya durumu mahiyet veya miktar itibariyle gerçeğe aykırı şekilde yansıtan belgelerin ise, muhteviyatı itibariyle yanıltıcı belge olduğu belirtilmiştir.

Vergi usul kanununa göre belge sahtekârlı̆̆ı iki şekilde gerçekleştirilebilmektedir. Bunlardan ilki hem belgenin hem de içeriğinin geçek olmaması durumudur. Bu tam anlamı ile sahte belgedir. İkincisi ise belgenin kendisinin gerçek olup, içeriğinin gerçeğe uygun olmamasıdır. Bu gibi hallerde alınan miktar veya tutar olduğundan farklı gösterilir. Sonuç olarak alınan belge yapılan işlemin gerçek durumunu yansıtmaz. Bu belgeler de muhteviyatı itibariyle yanıltıcı belgedir (HUD 2004:154).

\subsection{Vergi Ziyaı}

213 Sayılı Vergi Usul Kanununun 341. maddesinde; Vergi ziyaı, mükellefin veya sorumlunun vergilendirme ile ilgili ödevlerini zamanında yerine getirmemesi veya eksik yerine getirmesi yüzünden verginin zamanında tahakkuk ettirilmemesini veya eksik tahakkuk ettirilmesini ifade eder.

Vergi kaybının etkileri; mali etki, iktisadi etki ve sosyal etkidir. Mali etki ile devlet gelirleri azalır. İktisadi etki, vergi ödeyen mükellefler ile ödemeyenler arasındaki rekabet şartlarının bozulmasıdır. Sosyal etki olarak, vergi kaçakçılığ nedeniyle kamu düzeni ve vergi ahlakının bozulmasıdır. Dar anlamda vergi kaybı ise mükelleflerin vergi yükümlülüklerini, olması gerekenin altına indirmek istemeleri, vergi ödevlerini zamanında yerine getirmemeleri yada eksik yerine getirmeleri sonucu; verginin zamanında tahakkuk etmemesi yada eksik tahakkuk etmesidir (Aydın 2003:20)

\section{YÖNTEM}

$\mathrm{Bu}$ çalışmanın temel amacı, sahte veya muhteviyatı itibariyle yanıltıcı belgeleri kullanan (yasal defterlere kayıt edilmesi) işletmelerin karşılaşacakları muhtemel durumları göstermektir.

Araştırmanın amacına ulaşmak için sahte belge veya muhteviyatı itibariyle yanıltıcı belgelerin neden işletmeler tarafından talep edildiği, bu belgeleri kullanmanın ekonomiye etkileri, ayrıca sahte belge veya muhteviyatı itibariyle yanıltıcı belgelere karşı işletmelerin hangi hususlara dikkat etmesi gerektiği belirtilmiş olup yine de bu belgelerin kullanılması durumunda işletmelerin karşılaşacakları muhtemel olaylar örnek olay incelemesi ile açıklanmıştır.

\section{BULGULAR}

\subsection{Sahte Fatura Neden Kullanılır?}

İsletmeler tarafından farklı zamanlarda ve farklı nedenlerle sahte faturalar kullanılabilmektedir. Sahte fatura kullanmanın başlıca sebepleri şunlardır;

-Giderlerini veya maliyetlerini olduğundan fazla göstermek

-Çeşitli nedenlerle belgelendirilmemiş giderleri belgelendirmek,

-GVK'nın 94'ncü maddesindeki vergi tevkifatından kaçınmak,

-Haksız yere katma değer vergisi indiriminde veya iadesi talebinde bulunmak veya iade almak gibi sebeplerle, sahte belgeler kullanılabilir.

Sahte Belge ve Muhteviyatı İtibariyle Yanıltıcı Belgeyi kullanan işletme, giderlerini fazla göstererek ya da zamanla belgesiz olarak gerçekleştirdiği birtakım emtia/hizmet alımlarını ya da giderlerini belgelendirme gayreti ve çabasına girerek, kurumlar veya gelir vergisi matrahını düşürmek, daha az vergi ödemek, hiç vergi ödememek veya haksız yere indirimlerden ve istisnalardan (indirilecek KDV'yi yüksek gösterip daha fazla KDV iadesi almak gibi) istifade etmek amacı hedeflemektedir (Meriç; Karabalık; Durmuş 2012:64).

\subsection{Sahte Faturanın Ekonomiye Etkileri}

Sahte belgenin kullanılması; Hazineye intikal etmesi gereken vergi gelirlerinin azalmasına, Kayıt dışı ekonominin artmasına, Gelir dağılımının bozulmasına, neden olmaktadır. 
Bazı ekonomik faaliyetlerin kayıt dışında kalması, vergilerin eksik ya da hiç ödenmemesine neden olmakta ve sonuçta devletin vergi gelirlerini de azaltmaktadır. Devletin vergi gelirlerinin azalması sonucu doğan bütçe açıkları ya borçlanma ya da para basma yoluyla karşılanır. Bütçe açıklarının Merkez Bankası aracılığıyla para basılarak karşılanması, enflasyon oranın yükselmesine dolayısıyla gelir dağılımının bozulmasına neden olmaktadır (Sarılı 2002: 145).

Bir ekonominin ana gayesi kaynak dağılımında etkinlik sağlayarak, kaynakların verimli kullanılması, yeterli ve sürdürülebilir bir büyümenin sağlanarak işsizliğin azaltılması, öte yanda fiyat istikrarının sağlanarak gelir dağılımının adaletli oluşması, insanların refah düzeyinin yükselmesi, hayat standartlarının gelişmesinin (eğitim, sağlık ve kültürel imkanlardan daha fazla yararlanılması) sağlanması olarak özetlenebilir. Ancak bir ekonomide kayıt dışı ekonominin varlığı sayılan hedeflere ulaşmayı güçleştirmektedir (Uyanık 2013:33).

\subsection{Sahte Fatura Karşı Dikkat Edilmesi Gereken Hususlar}

Alınan mal veya faydalanılan hizmet karşılığında düzenlenen faturanın sahte olup olmadığı konusunda işletmeler tarafından aşağıda belirtilen hususlara dikkat edilmelidir (web 1)

-Mal ve hizmet alınan kişi ve veya kurumların gerçekten böyle bir faaliyeti olup olmadığından emin olunmalıdır. Gerekirse işyerleri görülmelidir.

-Maliye Bakanlığı'nın https://intvd.gib.gov.tr/internetvd/index.jsp adresinden E-Vergi Levhası ve vergi sicil numarası sorgulamalarını yaparak faal olup olmadıkları kontrol edilmelidir. Ayrıca mal alışı yapılan firmaların web siteleri kontrol edilmelidir.

-Adres, telefon ve internet bilgileri kontrol edilmelidir. Vergi numarasının yanında SGK işyeri numarası, Ticaret Sicil numarası gibi bilgiler de istenmelidir.

-Mal veya hizmet alınan kişinin verdiği faturanın kendisine ait olup olmadığına dikkat edilmelidir.

-Mal veya hizmet alımının gerçekliğini göstermek açısından gerçekten alınan malın fiilen alındığını ispatlayan varsa hamaliye belgesi, kantar fişi, ambar ve nakliye faturası, taşıma irsaliyesi, sevk irsaliyesi, taşıma sigortası, soğuk hava deposu faturası, konşimento vb. gibi belgeler muhafaza edilmeli, bu belgeler alınan mal faturası ile ilişkilendirilmelidir.

-Tutarı ne olursa olsun bütün ödemeler banka üzerinden gerçekleştirilmelidir. Banka aracılığıyla yapılan ödeme sırasında düzenlenecek belgede satıcının adı-soyadı/unvanı ile vergi kimlik numarasının doğru olarak yazılması önem arz etmektedir. Şirketlere yapılacak ödemeler ortaklar hesabı yerine şirket hesabına yapılmalıdır. Ayrıca ödemenin çekle yapılmış olması halinde de hamiline yazılı çek yerine nama yazılı çeki tercih edilmelidir. Kısaca ticari faaliyetlere konu ödemeler elden ve nakden değil, ispat gücü taşıyan; mükellef adına, yazılı çek, bono ve kaydi para (banka hesabına virman, havale, posta çeki) ile yapılmalıdır.

-Faturaların altında, faturayı basan matbaanın telefon ve vergi numarası bilgileri bulunmalıdır. Bu bilgileri teyit etmek için matbaa aranmalıdır.

-Sürekli çalışılmayan, tanınmayan firmalar ile mümkün olduğunca sözleşme yapılmalı, karşı firmalardan belgeler istenmeli ve bu belgeler saklanmalıdır.

\subsection{Sahte Belge Kullanmanın Yasal Yaptırımları}

Sahte belge kullanılması durumunda iki ihtimal söz konusu olmaktadır. Bunlardan birincisi, sahte belgenin bilerek (kasten) kullanılması, ikincisi ise bilmeden kullanılmasıdır. Sahte belgenin bilerek kullanıldığının iddia edilmesi durumunda sonuçları itibariyle çok ağır yaptırımlar uygulanmaktadır. Bu durumda;

KDV dahil sahte belge tutarının \% 10'u oranında özel usulsüzlük cezası kesilmekte, ziyaa uğrayan vergi geri istenmekte, ziyaa uğratılan verginin 3 katı tutarında vergi ziyaı cezası kesilmekte ve sahte belge kullanma fiilini işleyen kişi hakkında üç yıldan beş yıla kadar hapis cezası ile cezalandırılmak üzere dava açılmaktadır.

Bunlara ek olarak bilerek sahte fatura kullanıldığının iddia edilmesi durumunda, tarh edilecek vergi ve kesilecek cezalar için tarhiyat öncesi (özel usulsüzlük cezası hariç) ve sonrası uzlaşma hakkından yararlanılamamaktadır.

Sahte belgenin bilmeyerek kullanıldığının iddia edilmesi durumunda ise: KDV dahil sahte belge tutarının \% 10'u oranında özel usulsüzlük cezası kesilmekte, ziyaa uğrayan vergi geri istenmekte, ziyaa uğratılan verginin bir katı tutarında vergi ziyaı cezası kesilmektedir. Ancak bu halde, tarh edilecek vergi ve kesilecek cezalar için tarhiyat öncesi ve sonrası (özel usulsüzlük cezası hariç) uzlaşma hakkından yararlanılmaktadır.

Yukarıda zikredilen her iki durumda da, sahte belge kullanan mükellef “özel esaslara tabi” mükellef olarak kara listeye alınmaktadır. Buna göre Özel Esaslara alınan mükellefler ise;

-Vergi iadesi alma,

-Kamu ihalelerine katılma,

-Devlet teşviklerinden faydalanma, gibi konularda kısıtlamaya tabi tutulurlar.

Sahte belgeyi mükellefler ister bilerek kullansınlar, isterse bilmeyerek kullansınlar, sahte belgelerdeki KDV'leri indirim konusu yapmaları mümkün bulunmamaktadır. 


\subsection{Sahte Belge Kullanmanın İsletmeye Etkisi: Örnek Olay İncelemesi}

Örnek olay incelememizde şirket mahremiyetini korumak maksadıyla adı saklı tutulan gerçek bir firmanın verileri kullanılarak, bir örnek olay çalışması yapılmıştır. Örnek olayda, belirtilen firma ile ilgili olarak tespit edilen hususlar, ilgili kanun, tebliğ ve yönetmelik hükümleri dikkate alınarak değerlendirilmiştir.

(N) Ltd.Şti. 2018 hesap dönemi verileri;

- Kurumlar vergisi matrahı: 3.500.000,00-TL

- Hesaplanan Kurumlar Vergisi:770.000,00-TL

- 2018/Mart Ödenmesi Gereken KDV: 85.000,00-TL

Buna göre; (N) Ltd.Şti. 2018/Mart vergilendirme döneminde 600.000,00-TL + 108.000,00-TL KDV tutarlı sahte faturayı yasal defterlerine kayıt etmiş ve KDV'sini de indirim konusu yapmıştır. (N) Ltd.Şti. yasal defterlerine kayıt ettiği sahte fatura dolayısıyla;

-Giderlerinde/maliyetlerinde 600.000,00-TL artış sağlamıştır. Böylelikle kurumlar vergisi matrahı, sahte fatura tutarı kadar azalmış ve hesaplanan kurumlar vergisi (600.000,00*\%22=) 132.000,00-TL eksik beyan edilmiştir.

-2018/Mart dönemi indirilecek KDV tutarını 108.000,00-TL fazla hesaplanmış ve söz konusu tutar kadar ödenecek KDV eksik beyan edilmiştir.

(N) Ltd.Şti.'nin herhangi bir mal veya hizmet alışı olmadan maliyetlerini yükseltmek maksadıyla bilerek sahte fatura kullandığının vergi incelemesi yapmaya yetkili olanlarca tespit edilmesi durumunda;

-İ̧̧letmenin giderlerinde/maliyetlerinde 600.000,00-TL reddiyat yapılacağı için kurumlar vergisi matrahı, sahte fatura tutarı kadar artacak ve hesaplanan kurumlar vergisinin $(4.100 .000,00 * 22=)$ 902.000,00-TL olması gerekmektedir.

-2018/Mart dönemi indirilecek KDV tutarından 108.000,00-TL reddiyat yapılacağı için ödenmesi gereken KDV 193.000,00-TL olacaktır.

-KDV dahil 708.000,00-TL sahte fatura kullanıldığı için bu tutarın \%10 nispetinde $(70.800,00-T L)$ özel usulsüzlük cezasının kesilmesi gerekmektedir.

-Ayrıca (N) Ltd.Şti.'nin sahte belge kullandığı gerekçesiyle özel esaslara alınması gerekmektedir.

Kısacası yeni durumda (N) Ltd.Şti. sahte belge kullandığı için;

-132.000,00-TL kurumlar vergisi tarh edilmesi,

-396.000,00-TL kurumlar vergisi vergi ziyaı cezası (3 kat) kesilmesi,

-108.000,00-TL Katma Değer Vergisi tarh edilmesi,

-324.000,00-TL KDV vergi ziyaı cezası(3 kat) kesilmesi,

-70.800,00-TL özel usulsüzlük cezasının kesilmesi,

-Özel esaslara alınması gerekmektedir.

-Ayrıca (N) Ltd.Şti. müdürü hakkında bilerek sahte belge kullandığı gerekçesiyle hakkında Savcılığa suç duyurusunda bulunulacaktır.

\section{SONUÇ VE ÖNERILER}

Çalışmanın sonucuna göre, sahte fatura kullanma olayı ister bilerek isterse de bilmeyerek gerçekleştirilmiş olsun işletmeler açısından çok ağır maddi ve bazı durumlarda manevi yaptırımlara neden olmaktadır. Genelde işletmelerin daha az vergi ödemek maksadıyla başvurdukları sahte belge aslında işletmelerin kaçırdıkları vergi tutarlarının kat kat fazlasını geri ödemesine ve bazı durumlarda da hürriyeti bağlayıcı yaptırımlarla karşı karşıya kalabilmesine neden olmaktadır. Ayrıca sahte belge kullandığı tespit edilen işletmeler vergi dairelerince özel esaslara tabi tutulmakta olup bu durum işletmeler için para ile ifade edilemeyecek itibar kaybına sebebiyet verebilmektedir.

Devletin en önemli gelir kaynağı olan vergilerin hedeflenen düzeylerde toplanması, vergi kayıp ve kaçaklarının tespiti ve önüne geçilmesi ile sağlanabilir. Bu bağlamda vergi gelirlerinin artırılması, kayıt dışılığın azaltılması ve daha adil bir gelir dağılımının sağlanabilmesi için sahte belge düzenleme veya kullanma fiillerine karşı etkin bir mücadele verilmesi gerekmektedir.

\section{KAYNAKÇA}

Akdeniz, D. (2018). Sahte ve Muhteviyatı İtibariyle Yanıltıcı Belge Düzenleme ve Kullanma Suçunda Manevi Unsur. Adnan Menderes Üniversitesi, Sosyal Bilimler Enstitüsü Dergisi. 5(1): 90-105.

Aydın S. (2003). Vergi Kaybı, Nedenleri ve Yöntemleri. Vergi Sorunları Dergisi. 178:20

HUD (Hesap Uzmanları Derneği). (2004). Denetim Illke Ve Esasları. Ankara: Yıldız Ofset Yayınları

Meriç A., A. Karabalık ve Ö. Durmuş. (2012). Sahte Belge Nedir? Sahte Belge Sorununa Bakış, İrdelenmesi ve SMiYB Düzenleme/Kullanımı ile Mücadelede Çözüm Yolu Önerileri. Vergi Raporu Dergisi. 149: 59-74. 
Sarılı, M.A. (2002). Türkiye'de Kayıtdışı Ekonominin Boyutları, Nedenleri, Etkileri ve Kayıtlı Hale Getirilebilmesi İ̧̧in Alınması Gereken Tedbirler. Vergi Sorunları Dergisi. 167: 131-156.

Uyanık, O. (2013) İ̧̧letmelerde Vergi Kaçırma Yolları Ve Bunlara Karşı Güvenlik Müesseseleri. (Yayınlanmış Yüksek Lisans Tezi). Kayseri: Erciyes Üniversitesi Sosyal Bilimler Enstitüsü.

Web1: http://www.roedl.net/tr/tr/yayinlar/yazilar/sahte_belge_sahte_belge_kullanimi_ve_cezalari.html

01/08/1988 Tarih 28 Seri No.lu KDV Genel Tebliğ

193 Sayılı Gelir Vergisi Kanunu

213 Sayılı Vergi Usul Kanunu

3065 Sayılı Katma Değer Vergisi Kanunu 